\title{
From ant to stapler - 100 years of mechanical suturing in surgery
}

\author{
Antoni Ścierski \\ Department of General and Visceral Surgery, Grossburgwedel Hospital, Teaching Hospital of Medical Academy in Hanover, Germany
}

Videosurgery and other miniinvasive techniques 2010; 5 (2): 76-81

DOI: 10.5114/wiitm.2010.14209

\begin{abstract}
It has been 100 years since the first surgical stapler was built and used in surgery. The author presents a short anecdotal history of mechanical suturing.
\end{abstract}

Key words: mechanical sutures, history of the development of mechanical sutures.

Surgical staplers are commonly used in surgery, especially in visceral surgery. Today, it seems impossible to perform procedures without them. Also, the development of laparoscopic surgery would not have been possible without them. It has been 100 years since these instruments were first introduced into operating theatres. This anniversary is an appropriate occasion to remember the pioneers and the difficulties they encountered while developing and implementing the staplers.

The first idea to construct a mechanical suture device was conceived shortly after Billroth's successful first stomach resection in 1881 [1]. Already much earlier, in 1810, despite the then prevailing notion that stomach wounds do not heal, Maren had effectively demonstrated otherwise in his experiments on animals. In 1826, Lambert proved that serosa-toserosa sutures healed effectively and laid the theoretical foundations for performing what we call today 'an intestinal suture' [2]. The main challenge for surgeons operating in the late $19^{\text {th }}$ and early $20^{\text {th }}$ century, apart from the imperfect surgical techniques, was the asepsis of the operating field and, most of all, the abdominal cavity. The theses of Semmelweis were slowly gaining recognition; iodine and the carbolic acid propagated by Lister were progressively used in operating theatres. Unfortunately, neither substance could be used in an open abdominal cavity. The contact of gastric and intestinal contents with the peritoneum led mostly to fatal complications. Therefore a need emerged to construct a device that could help to reduce the leaks of gastric and intestinal contents into the abdominal cavity. At the turn of the century, Florian Hahn constructed a miniature machine for bowel suturing which was very similar to a conventional sewing machine. However, the suturing was so complicated that only a few surgeons, apart from the designer, were able to put this - more a toy than a medical device - to work. A few years later, in 1908, Prof. Humer Hültl from the University of Budapest, together with the mechanical constructor Victor Fischer, designed a new device for mechanical suturing (Figure 1) [3].

It was no longer based on the technique of suturing with needle and thread, but instead functioned similarly to an office stapler. The constructors managed to apply the mucosa-to mucosa suture, pioneering with their invention modern mechanical suturing. They used steel staples and performed a double stitch. The stapling was a 2-step process - first, the edges of the 
wound needed to be compressed and kept in place, then the staples had to be inserted into the tissue. The staples formed a $\beta$ shape when squeezed against an anvil on the other wing of the stapler. This machine weighed more than $4 \mathrm{~kg}$; operating it was quite cumbersome and required a physically strong assistant. Its use was also very expensive as after every procedure it had to be transported by train back to the factory and reloaded with staples. Then, boiling was used as a method of sterilization and it took a long time for the steel to cool down. To reduce the cooling time the stapler was rinsed with ether, which not only generated fumes in the theatre, but also further increased the cost of the surgery. Nevertheless, in 1909 Hültl reported 21 successful procedures. Later, Hültl's students, Mayer and Gransman, took the stapler to the United States and continued to work with it.

Aladar von Petz, a student of Prof. Kuzmik who, like Hültl, was working at the University of Budapest, had an opportunity to try the stapler. Challenged by the difficulties he experienced while using the device, he designed his own instrument and subsequently completed several successful procedures with it. Although bearing in mind that the honourable yet conservative body of Hungarian surgical experts had ridiculed the novel works of Schleich, Schandinn and Wassermann not that long before, the 32-year-old Petz decided to present his stapler at the $8^{\text {th }}$ Congress of Hungarian Surgeons in 1921 (Figures 2, 3).

Unlike Hültl, Petz reduced the number of staple lines and introduced silver staples. Among the few experts in the audience of his presentation a truly surprised Petz noticed Prof. Hültl, deep in thought. After

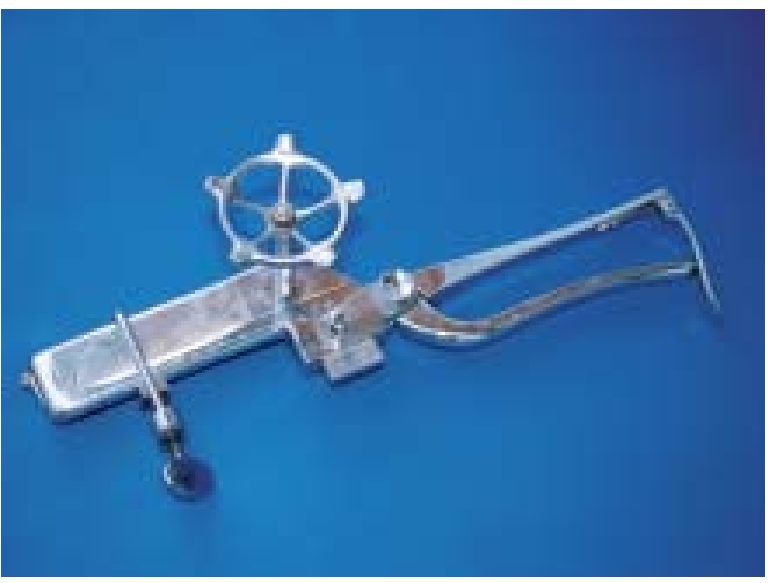

Figure 2. General view of Petz instrument

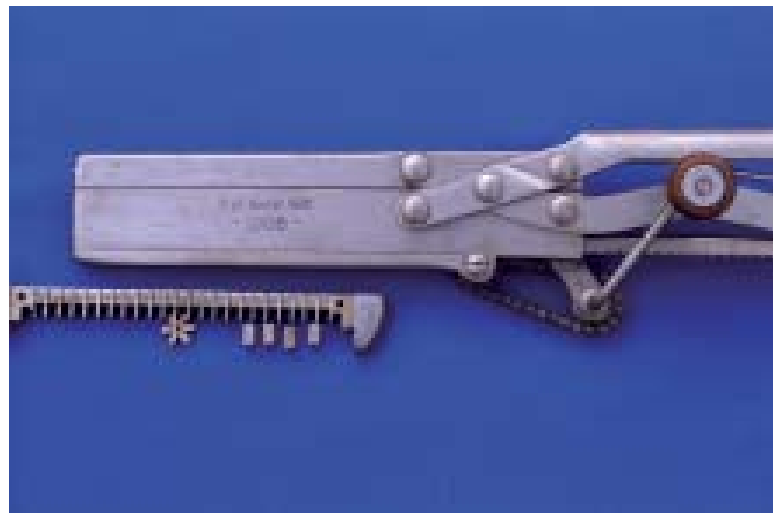

Figure 1. General view of Hültl instrument

the presentation, Hültl approached the younger surgeon, fished a leather glasses case out of his pocket and then, using Petz's instrument, stapled the case. "Your stapler is better", he said, and left the room. In consequence of this dramatic encounter, Hültl terminated the production of his device. Petz patented his stapler and 2 years later found for it an industrial manufacturer in Tutlingen, Germany. So it happened that many years before the introduction of Russian and American instruments, Petz's stapler became very popular among German surgeons. They even coined the verb "petzen", which, in the surgical jargon, became the synonym for mechanical suturing.

As is usually the case, the stapler found many advocates as well as opponents. At a presentation in London, one of the leading surgeons reckoned, "It's an excellent device, but whoever uses it, is a killer". Petz, famously sharp-tongued, retorted immediately, recalling the nonsensical objection accompanying the
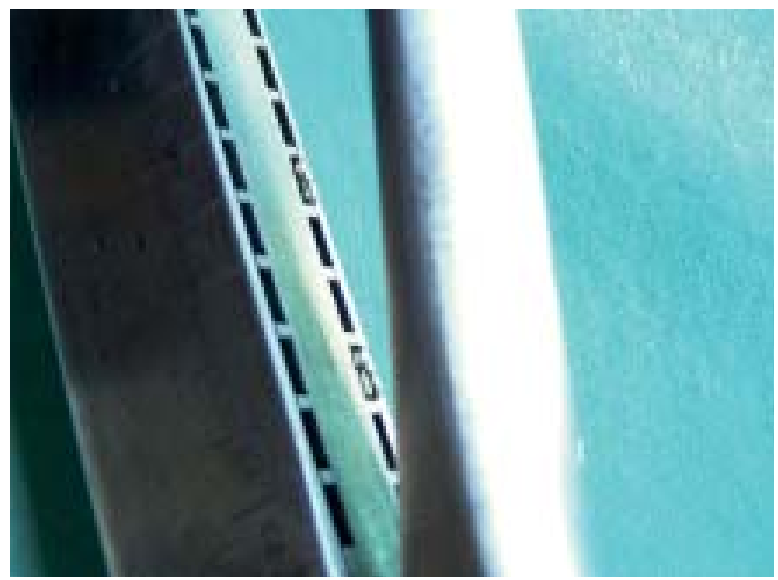

Figure 3. Open Petz instrument with silver staples 


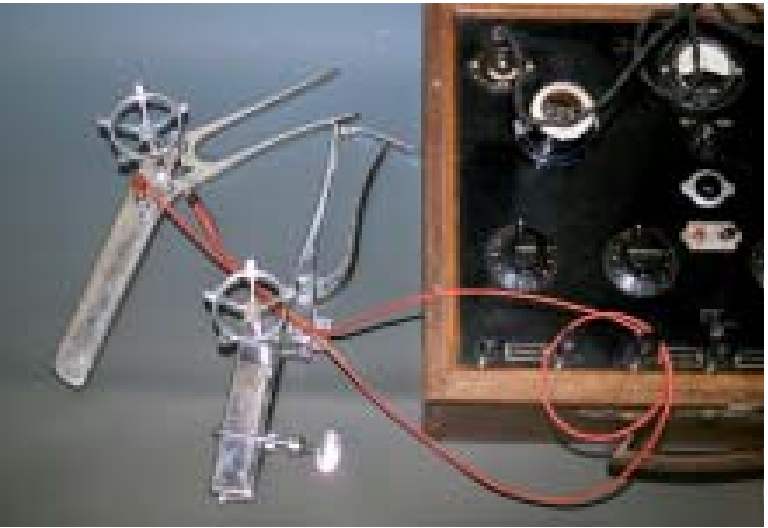

Figure 4. Petz instrument with current generator

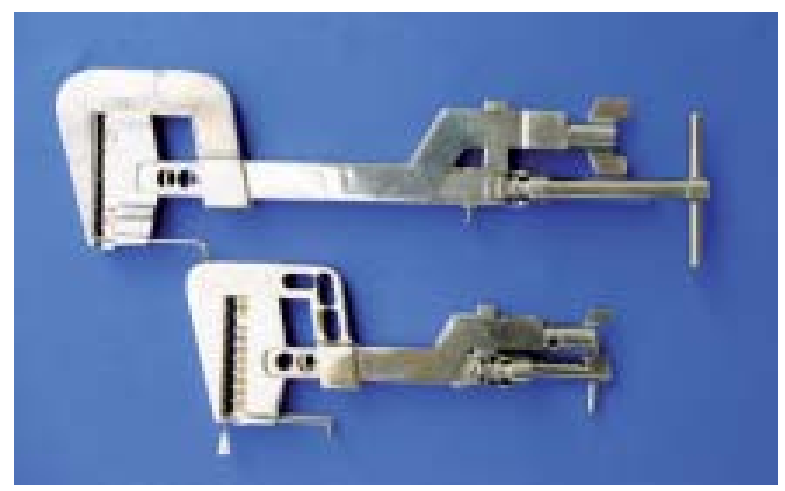

Figure 5. Russian stapler UTL-70 for applying 3 layers of suture and Russian linear staplers of second generation

introduction of the railways in England. It was believed then that people watching a train passing by with the "breakneck" speed of $25 \mathrm{~km} / \mathrm{h}$ would become insane. More pro and contra camps existed also in Italy. In Germany, Prof. Martin Kirchner, who made a name for himself with the hernia surgery technique Bassini-Kirchner, was the one who introduced the stapler to the operating theatres.

Accidentally, Petz himself struck a blow against his stapling invention. In order to reduce bleeding from the staple line he modified his instrument by integrating an electric current generator and bringing about an instant coagulation of tissue. Unfortunately, the new operating technique led to a growing number of necrosis incidents, and therefore Petz decided to drop it (Figure 4).

In the 1930s, the two prototype staplers were followed by other models. In 1931, Stefán Sándor patented his instrument that featured angled staples
- this innovative idea led later to the development of disposable staple cartridges [5]. Also, Friedrich Neuffer came up with his own version of a stapler. In 1935, Hans von Brucke from Innsbruck introduced the first instrument that was able to dispense staples from the cartridge and fasten them one by one with each squeeze of the handle. Outside of Europe, in 1937, M. Tomoda from the Japanese University of Kyushu modified Petz's model. He also used wide silver staples, but came up with the idea of applying adjustable pressure on the tissue while modelling a double staple line.

Petz's stapler became known in the USSR thanks to Prof. Petrowski, a former health minister who, in the 1950s, headed one of the departments at the university in Budapest.

In 1949, in the newly established Research Institute in Moscow, over 200 engineers, technicians, biologists, and physicians were working on the advancement of mechanical suturing. The staplers designed there were first tested on animals in the institute's own laboratory and then implemented in one of the cooperating city hospitals. A number of instruments were developed at that time, including the UTL-70 model. Originally designed for application on the bronchus, it proved to be as effective in abdominal surgery. The novelty of this instrument was that, in addition to the traditional double line stapling (mucosa-to-mucosa), a third staple line of serosa-to-serosa sutures (Lambert's mechanical suture) was applied in the same cycle. The USSC instruments from the TA series that we know from the more recent past resemble the look and functionality of those Russian staplers, especially the models of the follow-up generation, such as UO-40 and UO-60 (Figure 5).

The major factors that prevented general interest and adoption of the Russian staplers were the complicated procedure requiring manual loading of staple cartridges, limited production capacities and, consequently, purchase opportunities, lack of adequate training and insufficient information.

How did the Russian instruments get out from behind the Iron Curtain?

It is 1958. The dog Laika has been sacrificed on the altar of science. Budapest is still healing the wounds sustained 2 years earlier. In a few days Gagarin would fascinate the world with his space journey. The Cuban crisis is about to break out; the Cold War and the arms race are in full swing. In these tense times, the news 
leaks to the West that Russian scientists have managed to store blood and, three years later, transfuse it successfully. The U.S. rated this information as strategically very important and decided to send a delegation to attend a conference on haematology in Moscow and Kiev. One of the two surgeons appointed to the mission was Dr Ravitch, a good speaker of Russian, whose parents emigrated from Russia in 1918. The preparations and waiting for the Russian visas took months, but finally, with a clearly defined agenda of attending the conference and visiting two institutes of haematology in Moscow and Kiev, the delegation took off. Considering the historical context, it is a little surprising that the American surgeons were never admitted to any of these institutes. Instead, they were invited to visit Prof. Amosow's Institute of Thoracic Surgery in Kiev. There they were shown an procedure using staplers for closure of the bronchus, vessels and pulmonary tissue. These staplers were products of the Moscow Institute, and Ravitch, who had already been exposed to mechanical suturing earlier, became very excited. He actually managed to visit the institute in Moscow after all and, in the absence of the head of the institute, Prof. Ananiev, he was welcomed by his deputy, Prof. Babkin. While trying to purchase the staplers via official channels, all Ravich's attempts failed. As luck would have it, he found them unexpectedly elsewhere. While walking through the streets of Moscow, he came across a specialized store selling medical equipment. He could hardly believe his eyes when he saw the staplers simply lying there and available for general sale. In a country with fully socialized health care! The exorbitant price of 400 roubles per piece was hardly compatible with the socialized system, either... Ravich didn't think twice and purchased both staplers the store had in stock. Without any further formalities he acquired two UKB staplers, each elegantly packaged in a decorative wooden box lined with black velvet. After the customs formalities were completed, both instruments finally arrived in the United States. Ravich performed multiple experiments as well as lung resections using the instruments. He continued to work with them until 1963, reporting a total of 139 lung resection procedures, the development of fistulas in 3 cases and the development of thoracic empyemas also in 3 cases only.

Yet another coincidence led to the launch of surgical staplers manufacture in the United States and to the founding of a new enterprise, the forerunner of the company we know today as Covidien. In 1963,

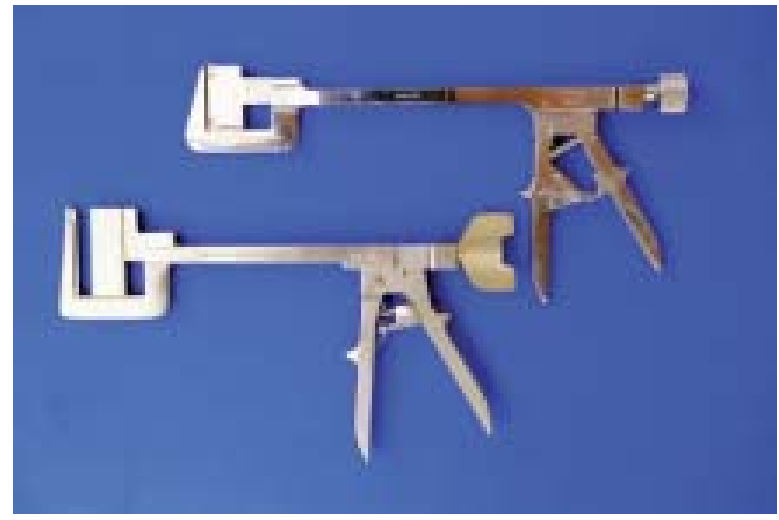

Figure 6. Upper instrument: Russian linear stapler UKL (manual loading of magazines). Lower instrument: linear stapler Auto Suture "old type", instrument type TA

Leon Hirsh, while visiting a patent lawyer in New York, noticed a quite unusual paper holder on his desk. In response to his query Hirsch was told the paper holder was actually an original Russian instrument for mechanical suturing and the lawyer acted as an agent and distributor of these instruments in the U.S. From a brochure he received, Hirsch found out about Dr Ravich and, although sceptical about the mechanical suturing device, he decided to contact the Russian surgeon. It was Ravich who directed Hirsch's attention to the main disadvantage of the Russian models: the cumbersome manual loading. Following a close examination of these staplers Hirsch arrived at a new solution. His model featured two separate elements: the stapler and a disposable staple cartridge. A few months later, he founded the United States Surgical Corporation (USSC), which was initially run with only 5-6 employees. The young company's focus was to improve and refine the Russian staplers (Figure 6).

In the early phase, USSC was manufacturing TA30, TA50, TA90 and GIA models. All of these instruments incorporated disposable staple cartridges that were pre-loaded and sterilized at the factory. The specially moulded anvil was designed to close staples made of stainless steel and, later, of titanium.

In 1957, Prof. Burzow from the Maxim Gorki University in Donetsk presented his functional circular stapler which was later followed by the PKS and SPTV models designed in the Moscow institute (Figures 7-9).

In 1977, USSC introduced its own first circular stapler, the model EEA, which was technically similar to the Russian instruments. The first procedure using the new USSC device was a stomach resection for 


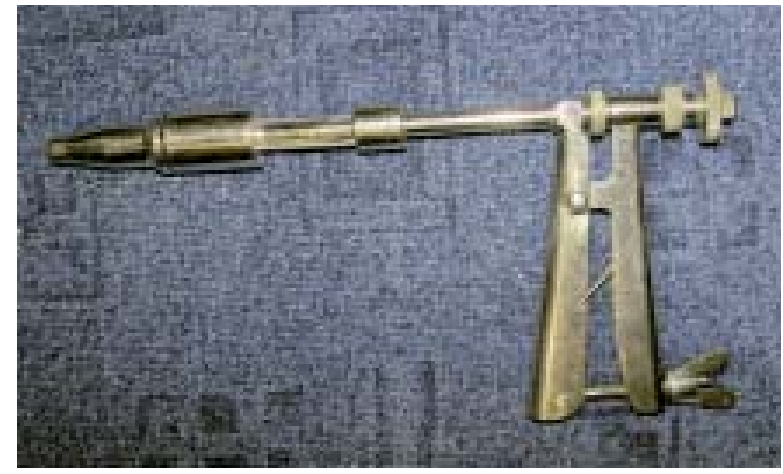

Figure 7. Burzow's circular stapler from 1957

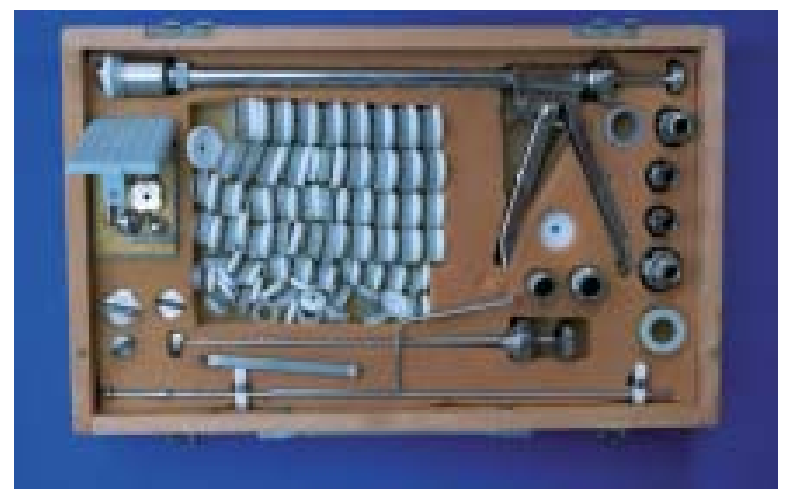

Figure 9. Circular stapler AKA-2, product of Institute in Moscow

gastric cancer performed on 6 June 1967 in New York. At that time, the staple cartridges still had to be loaded manually the day before the procedure and kept in sterilizing liquid overnight.

United States Surgical Corporation did not neglect to advertise its new instruments. In 1968, Prof. Steichen presented the instruments at a Surgeons' Congress in Dublin. The second "marketing trip" passed through several European countries and allowed numerous surgeons to become familiar with the staplers. At that time, the Russian instruments were not available outside the East European market. Taking into account the usual bureaucratic hurdles, they were obtainable in Poland and in the other countries of the Eastern Bloc. The instruments were wrapped in oily brown paper, packed in birch boxes and included an instruction manual only in Russian. Once the manual was deciphered, it was left to the surgeon to get to grips with the instrument. The staple cartridges had to be loaded manually and the process required a lot of patience, finesse, and practice. Lack of training opportunities offered by the manufacturer and dis-

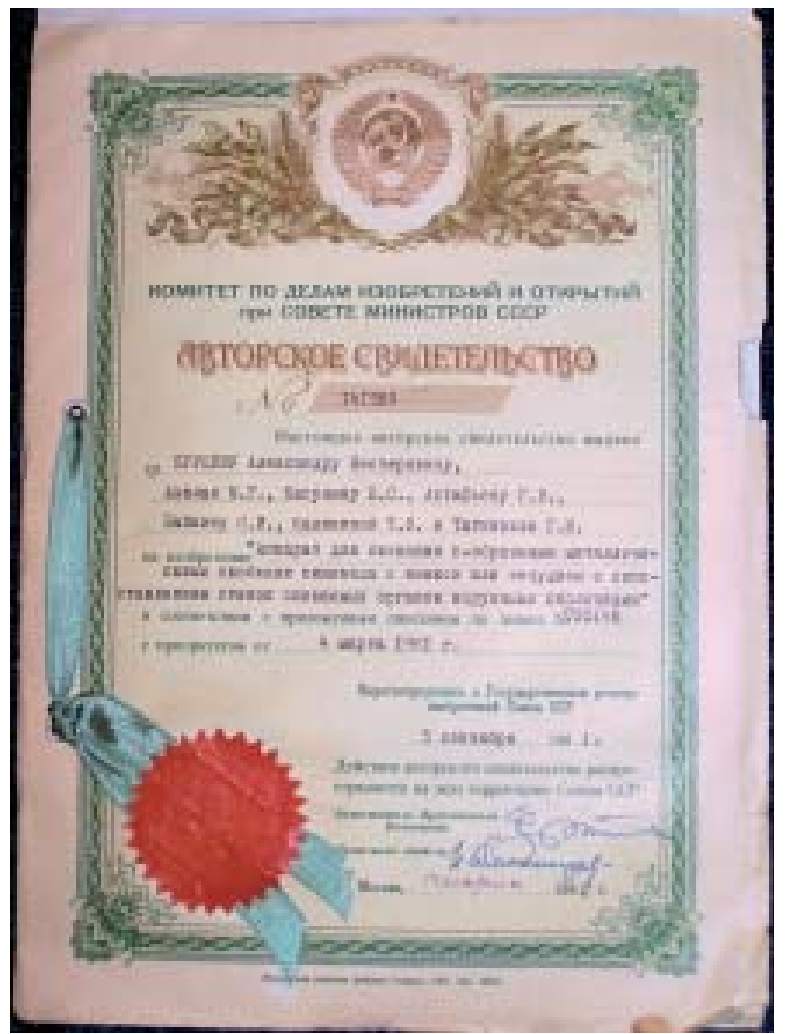

Figure 8. Burzow's patent for circular stapler

tributor was yet another reason why there was relatively little interest in these instruments on the East European market. In the case of the USSC instruments, the situation developed quite differently. An adequate advertising and marketing strategy, introduction of disposable staple cartridges and systematic progress in development paid off. Their staplers were to become widely accepted, and it would be impossible to imagine modern surgery and the development of laparoscopy without them.

Finally, what does an ant have to do with mechanical suturing? In early Hindu texts written approximately 2500 years ago by Susruta Samhita (also spelled Sushruta or Sushrutha), a famous ancient Indian surgeon, he described how the jaws of a black ant were used as surgical clips. After the ants had bitten and clamped together the edges of the wound with their jaws, their heads were twisted off, leaving the fixed jaws attached to the wound. This surgical sewing technique, or better said, this suturing technique, is still used today by some African tribes.

All photographs by courtesy of Dr. Heinrich Peyers, owner of the Private Museum of Medicine in Payne, Germany. 


\section{References}

1. Novák K. Theodor Billroth Titan der Chirurgie aus tschechischer Sicht. Publisher: Novák i Österreichische Gesellschaft für Chirurgie 1999.

2. Harder F, Kocher T. Geschichte und Entwicklung der Anastomosentechnik. in Anastomosen-Technikern im Magen-DarmTrakt Auto Suture Deutschland GmbH. Kocher T, Harder F (eds) 1999; 6-7.

3. Hültl H. Kongress der Ungarischen Gesellschaft für Chirurgie, Budapest, Mai 1908. Poster Med Chir Presse 1909; 45: 108-10, 121-2.

4. von Petz A. Zur Technik der Magenresektion. Ein neuer MagenDarmnnähapparat. Zentralbl Chir 1924; 51: 179-88.

5. Sándor S. Magen-Darmnaht mit Metallklammern nach Hültl und ein neues Nähinstrument. Zentralbl Chir 1936; 63: 1334-8.

6. Androsov PI. Atlas of surgical operations by means of suturing instruments. $2^{\text {nd }}$ ed. Moscow, Vneshtorgizdt.

7. Steichen FM, Ravitch MM. Stapling in surgery. Chicago, Year Book Medical Publishers 1984. 